Article

\title{
Repositioning the Racial Gaze: Aboriginal Perspectives on Race, Race Relations and Governance
}

\author{
Daphne Habibis ${ }^{1, *}$, Penny Taylor ${ }^{2}$, Maggie Walter ${ }^{1}$ and Catriona Elder ${ }^{3}$ \\ ${ }^{1}$ School of Social Sciences, University of Tasmania, Hobart, TAS 7001, Australia; E-Mails: d.habibis@utas.edu.au (D.H.), \\ maggie.walter@utas.edu.au (M.W.) \\ ${ }^{2}$ Larrakia Nation Aboriginal Corporation, Darwin, NT 0810, Australia; E-Mail: penny.taylor@larrakia.com \\ ${ }^{3}$ Department of Sociology and Social Policy, University of Sydney, Sydney, NSW 2006, Australia; \\ E-Mail: catriona.elder@sydney.edu.au \\ * Corresponding author
}

Submitted: 30 October 2015 | Accepted: 22 January 2016 | Published: 23 February 2016

\begin{abstract}
In Australia, public debate about recognition of the nation's First Australians through constitutional change has highlighted the complexity and sensitivities surrounding Indigenous/state relations at even the most basic level of legal rights. But the unevenness of race relations has meant Aboriginal perspectives on race relations are not well known. This is an obstacle for reconciliation which, by definition, must be a reciprocal process. It is especially problematic in regions with substantial Aboriginal populations, where Indigenous visibility make race relations a matter of everyday experience and discussion. There has been considerable research on how settler Australians view Aboriginal people but little is known about how Aboriginal people view settler Australians or mainstream institutions. This paper presents the findings from an Australian Research Council project undertaken in partnership with Larrakia Nation Aboriginal Corporation. Drawing on in-depth interviews with a cross-section of Darwin's Aboriginal residents and visitors, it aims to reverse the racial gaze by investigating how respondents view settler Australian politics, values, priorities and lifestyles. Through interviews with Aboriginal people this research provides a basis for settler Australians to discover how they are viewed from an Aboriginal perspective. It repositions the normativity of settler Australian culture, a prerequisite for a truly multicultural society. Our analysis argues the narratives of the participants produce a story of Aboriginal rejection of the White Australian neo-liberal deal of individual advancement through economic pathways of employment and hyper-consumption. The findings support Honneth's arguments about the importance of intersubjective recognition by pointing to the way misrecognition creates and reinforces social exclusion.
\end{abstract}

\section{Keywords}

Aboriginal; Australia; indigenous; race; recognition theory

\section{Issue}

This article is part of the issue "Social Inclusion and Indigenous Peoples", edited by Pat Dudgeon (University of Western Australia, Australia), Waikaremoana Waitoki (University of Waikato, New Zealand), Rose LeMay (Wharerātā Group, Canada) and Linda Waimarie Nikora (University of Waikato, New Zealand).

(C) 2016 by the authors; licensee Cogitatio (Lisbon, Portugal). This article is licensed under a Creative Commons Attribution 4.0 International License (CC BY).

\section{Narratives, Truths and Recognition}

The past 25 years has seen significant public debate in Australia about the need for constitutional, legal, polit- ical and cultural change in how the nation state and its White settler population should recognise its First Peoples. One outcome of these arguments has been comprehension of the need to improve public understand- 
ing between First Nation peoples and the settler Australian $^{1}$ mainstream (Worby \& Rigney, 2006). But while researchers know how mainstream Australia views Aboriginal people and culture there is a corresponding lack of Aboriginal perspectives (Dunn, Kamp, Shaw, Forrest, \& Paradies, 2010; Goot \& Rowse, 2007; Mellor, 2003; Walter, 2012). As colonised subjects, Aboriginal peoples have a history of being silenced by mainstream institutions and have few opportunities to tell their own truths (Bretherton \& Mellor, 2006; Larkin, 2011). This article seeks to disrupt this dynamic and address the lack of balance in narratives by presenting Aboriginal truths about settler Australians. This is not simply about lack of voice but also about radical differences in understandings and value systems (Boyd, 2009). Drawing on a series of interviews with Aboriginal people in Darwin, and working with ideas of the politics of recognition (Honneth, 1995, 2001; Morrison, 2010; Taylor, 1992), we argue that for good race relations, and broader social inclusion, settler Australians need to understand that while they are judging Aboriginal peoples, so Aboriginal people are evaluating and judging their lifestyles and values.

In the last decade, reconciliation has become one of the main prisms used in Australia to facilitate Indigenous social inclusion (Gunstone, 2007). Yet for reconciliation to occur there needs to be a profound shift in the dominance of settler narratives in all aspects of national life (Fraser, 2001). Meaningful reconciliation requires repositioning the normativity of settler Australian perspectives so that the dominant culture comes to understand the relative nature of its own cultural attachments (Hage, 1998; Saxton, 2004). This is a prerequisite for a truly socially inclusive community. Understanding Aboriginal viewpoints also provides dominant groups with an opportunity to see how they are viewed from the outside. This is especially important in regions with substantial Indigenous populations where the visibility of Aboriginal people make race relations a matter of everyday discussion and experience.

\footnotetext{
${ }^{1}$ Race relations in Australia are complex. In the twenty-first century the dominant group are still Australians with British heritage. A long and substantial migration programme means a significant minority have European, Middle Eastern, South American, South East and East Asian heritage. There is growing legal recognition of the Indigenous people of Australia, especially through land rights, but they are still marginalized in many ways. In this article we focus on the relationship between Aboriginal people and the dominant group of colonisers-the settler Australians. We use these non-symmetrical terms to alert readers to the specificity of our analysis. However, at times we also use the term White to refer to the dominant political and legal and cultural national narrative. The term White was initially used to communicate with participants, who were also invited to use their preferred term in the research interaction.
}

Aboriginal people are a public in their own right but we know very little about Aboriginal perspectives on settler Australian culture and settler Australian people. National surveys on the Australian public's values, priorities and attitudes have, to date, provided little opportunity for analysis of Aboriginal views, since the small proportion (2.5\%) of the Aboriginal and Torres Strait Islander population rarely permits sub-group analysis. Qualitative studies have tended to focus on the views of the settler Australian majority.

The lack of opportunities for Indigenous peoples to tell or speak their own truths (Bretherton \& Mellor, 2006; Larkin, 2011) means that, typically, settler Australians speak for, to and about Aboriginal Australians, leaving Aboriginal people with few opportunities to describe their own subjectivities and provide counter narratives. Drawing on Langton's (1993) classic essay Elder's research has shown how the settler Australian public consumes representations of Aboriginal people through current affairs, sport and entertainment media. This produces a sense of knowing about Aboriginal lives without ever communicating with Aboriginal people (Elder, 2007). Aboriginal people appear only as the dystopian or romanticised objects of mainstream stereotypes resulting in a denial of their reality as subjects possessing their own views and opinions (Langton, 1993).

Unbalanced intercultural exchange reflects a situation where most settler Australians have an unrealistic understanding of the diversity of Indigenous lives, Indigenous familial and community relationships or the complexity of their interactions with settler Australian culture. There is little awareness of the existence of a small but growing middle class (Langton, 2012; Prout, 2012) and little understanding of the sizeable proportion of Aboriginal people who are of mixed descent. Holmes' (2008) research on how non-Aboriginal people in Darwin view geographically mobile Aboriginal people reveals the inaccurate ideas that prevail and how this, together with an inability to recognise the cultural nature of their own values, beliefs and attitudes, contributes to difficulties in improving Aboriginal health and well-being. Quantitative research tells a similar story. A national survey found that for non-Indigenous respondents, fewer than half believed Indigenous people are mostly disadvantaged and 20 per cent believed most Aboriginal people live in remote locations (Stolper \& Hammond, 2010, p. 21).

Such beliefs are maintained despite the evidence to the contrary. Australian Bureau of Statistics (ABS) (2010) data reveal the gross weekly equivalised household income of Indigenous households remains at about two-thirds the income for non-Indigenous households and the Aboriginal and Torres Strait Islander population is predominantly urban (75\%). A key reason for this disjuncture between settler Australian stereotypes and the lived reality of Aboriginal lives is 
that though the two groups may live in the same city, they are socially, culturally, economically and spatially segregated from them. The socioeconomic separations in health, well-being, employment and income are aligned with spatial ones so that Aboriginal peoples and settler Australians might live in the same places, but not in the same spaces. For most Australians, Aboriginal people are not their neighbours, their workmates, their service providers, or their friends (Walter, Taylor, \& Habibis, 2011).

The theoretical frame of Whiteness helps us to make sense of this disconnect between White settler Australians and Indigenous realities. Whiteness theory stresses that Whiteness is not so much a biophysical phenomenon but rather a multi-layered social construct: an identity more than skin colour. Ruth Frankenberg (1993) posits Whiteness as dominant across three dimensions: a location of structural advantage or privilege, a set of cultural practices that are unmarked and unnamed; and standpoint, the worldview from which those who are White understand themselves and those who are not White (Frankenberg, 1993, p. 1). Frankenberg's three tenets are manifest in Australian society. Australian social structures produce and reproduce a position of privilege for those who are White as well as a position of disadvantage for those who are non-White. Second, the hierarchy of racial stratification that produces the privilege of Whiteness is maintained and reproduced by formally unrecognised, but entrenched cultural practices reinforced by the near universal Whiteness of our political, public and private sector leaders. The norm of Whiteness is also daily reflected back via Australian media and culture (Walter, Taylor, \& Habibis, 2011) which largely excludes Aboriginal and Torres Strait Islander peoples except as objects of cultural curiosity. As Australian Indigenous peoples, Aboriginal and Torres Strait Islanders are embedded in the most disadvantaged structural location. They are culturally and socially excluded and carry a burden of disregard via the pejorative framework through which many settler Australians view Aboriginal people and Aboriginal issues. The seeming universality of Whiteness, in White majority countries such as Australia, mask both its privilege and the dis-privilege of those who are not White. White people tend to see their own race as less striking or novel than that of others, and while they note the inequality in other lives they are less likely to acknowledge its connection to the privilege in their own, instead adhering to an individualistic ideology in relation to their own success (Hartmann, Gerteis, \& Croll, 2009).

Stigmatisation and the refusal to represent or see Aboriginal heterogeneity by Settler Australians has serious implications for everyday lives and Aboriginal identity (Rowse, 2009). It increases racial tensions, reduces non-Aboriginal empathy (Holmes, 2008), maintains informal racial segregation and contributes to ra- cial prejudice and racial violence. This contributes to the location of Aboriginal people at the bottom of almost every measure of health and well-being in Australia (Australian Government, 2012). These dynamics play a critical role in compounding and perpetuating Aboriginal disadvantage (Cunneen, 2008; Miller \& Savoie, 2002).

Paradoxically, the connection between the "burden of disregard", and marginalisation is widely understood within Australian society. More than 90 per cent of Indigenous respondents, and around 75 per cent of nonIndigenous respondents agree that lack of respect for Indigenous people is implicated in Indigenous disadvantage (Stolper \& Hammond, 2010). Honneth's (2001) recognition theory explains this connection as due to the moral-psychological dimension of cultural values and their deeply felt nature. When minority cultures are misrecognised or not respected, this is personally wounding because cultural beliefs have a normative dimension involving intuitive feelings of social justice (Lister, 2004). Experiences of cultural denial reduce social inclusion because they may result in feelings of self-blame and social discontent. This helps to explain Aboriginal disengagement from mainstream services and the resistance of some Aboriginal people to state interventions where these violate embedded cultural beliefs (Habibis, 2013; Holmes, 2008).

This understanding of the impact of misrecognition on intersubjective relations has been questioned by Fraser's "bifocal" approach which emphasises "status" rather than "identity". Both Honneth and Fraser seek to specify the ways in which the imperfect realisation of liberal values of 'equal autonomy and moral worth of human beings' (Fraser \& Honneth, 2003, p. 224, cited in Thompson, 2005, p. 89) are realised in present social conditions. But while Honneth suggests the process of recognition in terms of a psychic or cultural understanding is linked to or prefigures other aspects of recognition, including a shift in resource allocation, Fraser (2000) emphasizes the ways in which a shift to a focus on identity politics might have a negative effect on plans or frameworks focused on equality in terms of economic redistribution. Fraser acknowledges the validity of Honneth's (2001, p. 29) claims about how the denial of culture shapes subjectivities, but focuses on the importance of institutional recognition for social inclusion because of its impact on material inequality. She argues distributional inequality is necessary to improve social inclusion, so it is the failure of the state to recognise unfair cultural patterns that should be addressed.

Fraser's view is powerful in its double vision of both economic and cultural injustice, and its capacity to recognise injustice without a demeaned group itself naming it, and has been used to argue that the effects of economic or institutional injustice are different from episodes of self-perceived misrecognition (Zurn, 2003, 
pp. 533-534). But Honneth's work explains how everyday interactions with the state work to reproduce social exclusion. This paper provides some insight into this debate by revealing how the complex interconnections between subjective experiences of misrecognition and institutional arrangements work to reinforce and sustain Aboriginal social exclusion.

\section{Methods}

\subsection{The Darwin Context}

Darwin is the major city of the Northern Territory and Aboriginal people currently make up about 10 percent of Darwin's population (ABS, 2013a, 2013b). The city is built on the traditional lands of the Larrakia people and a long history of Aboriginal oppression and dispossession. The first group of 139 settler Australians arrived in Darwin in 1869 when the Territory was controlled by the colony of South Australia. The Territory was ceded to the Australian Commonwealth in 1911 but not before the South Australian legislature passed the Northern Territory Aboriginals Act (1910). This act and subsequent legislation and ordinances controlled nearly every aspect of Aboriginal peoples' lives. All Aboriginal children were deemed wards, Aboriginal people were denied the vote, restrictions were imposed on where people could live and visit and who they could marry. Children were separated from parents, frequently permanently, and compounds were set up to contain Aboriginal people away from settler Australian populations (Chesterman \& Galligan, 1997).

It was not until 1978 that many of the acts and ordinances that dominated Aboriginal life began to be dismantled (Chesterman \& Galligan, 1997). This segregation and the restrictions are in living memory of many Darwin Aboriginal residents. The legacy of socioeconomic inequity continues through to current generations as shown by data from the 2011 Census of Population and Housing. Compared to non-Indigenous Darwin residents Aboriginal people are more than three times as likely to be unemployed, have higher numbers of people resident per household, are more likely to be homeless, have a much lower median income, are more likely to live in rental accommodation and have lower educational levels (ABS, 2013a, 2013b).

\subsection{The Methodological Context}

Any project that concerns First Nations peoples must ensure that it supports their aspirations and, as a minimum, it should provide opportunities for their involvement in it. However as Karen Martin notes much of the research undertaken with Aboriginal people to date has been what she calls "salvage research" or research where Aboriginal peoples are objects, not those who frame the research question and trajectory (2008, pp. 25-27). This project shifts this tendency. It was initiated by Larrakia Nation, which is the peak advocacy and support agency for Darwin's traditional owners. Larrakia staff, in collaboration with the University of Tasmania academics took extensive measures to ensure the research is driven by Aboriginal knowledge, concerns and agendas. Shawn Wilson's (2008) methodological approach of research as ceremony is a good way of understanding the type of approach we used, as is Linda Tuiwahi Smith's argument that "Indigenous methodologies tend to approach cultural protocols, values and behaviours as an integral part of methodology" (2001, p. 15). Based on these epistemologies the research team is a mix of Aboriginal and White settler researchers with project methods developed to address the limitations of Western research methods when researching Indigenous populations (Guilfoyle, Coffin, \& Maginn, 2010). Our work was shaped by an Indigenist approach that understood

the process is the product. If you teach or do research within the traditions of the circle, which is inclusive, participatory, proactive...then you're teaching the individuals within that circle to become participatory, inclusive and so forth. (Wilson, 2008, pp. 103-104)

To fulfil this goal the research employs a mixedmethods approach informed by the need to develop methods that are respectful of Aboriginal ontologies, cultural norms and emphasize relational rather than transactional social relationships. The broader study used qualitative interviews alongside the use of social media and survey. We developed a community Facebook site open to all Indigenous people living in the Greater Darwin area. It promoted participation in the project and provided Aboriginal perspectives that were used in the research instruments. The findings from these two methods were used to develop a survey instrument that was applied to a sample of 400 of Greater Darwin Indigenous residents and visitors with sociodemographic characteristics matched as closely as possible to those of the Indigenous population of the Greater Darwin area that was in progress at the time of writing.

This paper reports on the qualitative interview phase of the research. This phase comprised up to six repeat interviews with a group of 44 respondents who meet the study criteria of identifying as Aboriginal and/or Torres Strait Islander, living or visiting Darwin and being over eighteen years old. To ensure diversity a sampling frame was applied based on the 2011 Census for Darwin. Variables included age, gender, housing tenure, traditional owner/other, income source and Aboriginal only or mixed descent.

Data collection took place over six months in 2015. Attrition was low with only eight withdrawals, so that 
at the end of this phase of the study there were thirtysix respondents. They were a highly diverse group that included employed home owners and unemployed long grassers, and were drawn from all adult age and income groups. Some were long grassers, others were political activists, some were carers and others were artists. They included stolen generation men and women who had lived all their lives in Darwin, and others who were regular visitors from remote communities. Meeting repeatedly and building relationships over an extended period was designed to strengthen the quality of information shared with the researchers and was more respectful of the knowledge sharing involved (Roulston, 2010). In most cases these interviews were conducted by two interviewers, one Aboriginal and one White. To reflect Aboriginal cultural norms we also paired male respondents with male interviews and female respondents with female interviewers.

These measures addressed concerns that research with Indigenous populations often carries expectations that it is the Indigenous people who need to step outside their cultural norms. Their purpose was to minimize this tendency by providing an Indigenous majority in the conversation. The Indigenous researchers brought their own cultural knowledge to the engagement and ensured that the questions were framed by Indigenous world views. The White researchers also actively reflected on how Whiteness might be shaping their understandings and approaches throughout the interviewing phase. By visiting respondents a number of times, this part of the research addressed the relational nature of Aboriginal engagement with research and allowed respondents to develop discussion points and steer contributions in an iterative process. It provided time for the development of a trusting relationship between respondents and interviewers and encouraged genuine openness and sharing. Respondents had time to consider their responses and to discuss the issues with family and friends. The interviews also employed a conversational, "yarning" interview style (Bessarab \& Ng'andu, 2010) that allowed respondents' concerns and interests to direct the interaction and followed their interactional style, including the use of stories to describe their views. Translation services were available for respondents who preferred to speak in their own language. To support communication we employed a visual strategy alongside the interview schedule in which photographs and images were used to explain points for discussion.

At the completion of the interviews the data were entered into the qualitative software package NVivo and underwent two stages of coding. In line with the Indigenist methodological approach the group who participated in this process were the interviewers as well as the lead researchers. Coding was undertaken individually and through group meetings to ensure shared visions and ongoing participatory practices ${ }^{2}$. The process of coding the data was two stage. The first was structural coding, a mode of coding that mimics the interview questions and enables date to be sorted into the main areas of the project. ${ }^{3}$ This was followed by thematic analysis. As is usual some of the themes were ones we had presumed would emerge while others came to light through the process. Some of the key thematic codes that emerged are the ones that run through our analysis in this paper-trauma, the enduring impact of dispossession, feelings of national exclusion, and straddling two worlds.

\section{Findings}

The findings reported in this paper concentrate on two themes identified in the analysis of the interview data that most closely relate to social inclusion and social exclusion. The first is the sense of continued dispossession and disenfranchisement experienced by our respondents and their resistance to this. The second is responses to the values and aspirations of the White settler majority to which they are expected to conform for any chance of social, cultural and economic inclusion.

\subsection{Theme 1: Dispossession, Exclusion and Resistance}

Respondents described Darwin as a pot of different ethnic groups. R1 noted:

Well as in the city, you know you are going to have that broad spectrum of countrymen coming from everywhere...and on the other side of the coin you've got the Europeans, which we got a lot of Irish as present for the gas...you've got the tourists, you've got Taiwanese, you've got Chinese-you name it. Darwin is a melting pot and a very diverse multicultural place.

However, it not always seen as a pot that is melting. Respondents noted that they belong to Darwin, but were concerned at how rapidly it is changing in ways that provide even fewer spaces for Aboriginal people. R1 observed: "I know a lot of Aboriginal people that are, I mean from a work perspective living on the beach and stuff like that you know. Living day to day you know-you're subject to violence...." Thinking about the issue from a broader perspective R3 referred

\footnotetext{
2 The data were coded by Catriona Elder, Alex di Georgio, Daphne Habibis, Kelly Pollard, Penny Taylor, and Maggie Walter. ${ }^{3}$ The structural codes for the study were: Darwin and belonging, recognition, values, beliefs and behaviours, White privilege, views on Aboriginal/White relations, understanding Aboriginal/White attitudes and behaviours, relationships between Aboriginal peoples, mainstream politics, Aboriginal and White law.
} 
to the way Aboriginal people had little space in the national story: "when people are talking about Australians or Australia you know the exclusion of Indigenous people from that picture."

Along with other participants R1 suggests that there should be much more Aboriginal control and involvement in decisions about the city. He uses the ideas of "working with" Larrakia and "giving over responsibility" to describe what should happen. Many were concerned for Larrakia people to have greater involvement as the traditional owners who have a right to a say in the city's future. As one woman put it: "They do a lot of things wrong, the non-Indigenous, and what the great wrong (is) not acknowledging the Larrakia people" (R26).

One of the strongest themes in the data is an overwhelming experience of loss that is multi-layered and accompanied by a sense that addressing the issues is beyond the control of participants. Their perception is that the odds are stacked too heavily against them and most settler Australians don't really care. The sense of imbalance between effort and achievement is captured by R15:

We're fighting, fighting all the time and none of us mob are winning. Our old mob are dead and gone, the mob that used to fight for our rights, you know. You get asked 'Where's the fair go?' There is no more fair go.

R20 describes how White people are uncaring in the face of Aboriginal need:

Most people that are White are just so one-sided type of thing. Like they don't care why those Aboriginal people are in the bushes ${ }^{4}$ and they don't give a fuck about nothing.

Fundamental to the sense of loss and despair is the perception of the continuing intrusion of settler dominance on Aboriginal land and the impact this has on Aboriginal people. This is explicit in R37's account of how Balanda (a widely used term for settler Australians amongst Aboriginal peoples in the Northern Territory) activity affects Yolngu people, who are the traditional custodians of East Arnhem Land in the north eastern tip of the Northern Territory:

But Balanda doing it the wrong way and destroying this country. That's why Yolngu old people-they will just all die out.

But when asked whether they felt race relations had improved, the prevailing view was that there had been

\footnotetext{
4 This refers to homeless Aboriginal people living in open
} parklands in and around Darwin. some changes for the better. One respondent observed: "A lot of Aboriginal people [are] working with White people now, so a lot of attitudes have changed. It's not so bad now [as] it was probably 20 years ago" (R15). They described positive experiences with some settler Australians with many remarking that those settler Australians who had mixed with Aboriginal people growing up, or through work, tended to be more understanding and appreciative of Aboriginal cultures and people than those who knew nothing about them. There was also a shared view that many tourists were friendly and appreciative of Aboriginal culture.

These positive experiences were heavily outweighed by accounts of everyday racism, discrimination and disrespect. This occurred in daily encounters and was integral to Darwin life. White settlers dominate just by being White, whereas they struggled to make their voices heard. They were acutely aware that to operate in everyday life they needed White cultural capital. They saw how an understanding of White culture, the unacknowledged sense of cultural belonging and the possession and use of language, gave White settlers a power and authority that they did not have. This was related to a perception that the way settler Australians think they are better than Aboriginal people is a constant presence in their interactions with them. They described feeling constantly judged and found wanting. As one respondent put it: "They all stereotype us, you know. And I say to them 'I've paid taxes for 35 years you know. I pay your children's Centrelink too'" (R11).

\subsection{Theme 2: Incompatible Worlds, Rejection and Resistance}

Almost all respondents described how Indigenous and non-Indigenous people occupy different physical and social worlds. Different values and cultures make mixing difficult resulting in a lack of interest in social interaction with settler Australians. Most interactions described were instrumental. They described feeling uncomfortable in public places, and being made to feel different in shopping malls and as if they didn't belong because of the way they were stared at or followed round by security guards. One woman observed: “I don't feel comfortable going to a restaurant, going to the shopping centre....I'm not used to it. I'm just scared of them staring at us....Why? Because White people are all the same" (R29). Almost all respondents said they are most comfortable in spaces that are predominantly Aboriginal because they feel safe and able to be themselves.

Respondents spoke of the difficulty of walking in two worlds. This comment was typical: “Daily I'm juggling with who I am...how I talk, how I act and look and whatever. So you get it from the Whitefellas, you know, that you can't talk good English, and then these blackfellas, 'Why are you acting White, talking White?"” 
(R14). R14's comment shows the experience of some respondents that even when they speak the same language as that of settler Australia it is rejected as not good enough. It demonstrates the impossibility of negotiating two worlds because if they become White they are accused of betraying their culture, but if they try to be White they can never be White enough. They feel they have to constantly choose between how to behave, depending on whether they are in a White or black space and that whatever their choice it's not enough.

This incompatibility is a barrier to success or a sense of belonging. To succeed or fit into settler culture, respondents felt they have to sacrifice the things that are important to them and which define who they are as an Aboriginal person. An everyday example is given by R13 who shares the common story about being made to feel uncomfortable by walking barefoot in a shopping centre:

Well like me I will be like walking around barefoot into the shopping centre here for instance you know and then people will be looking at me differently, like "why doesn't he have any shoes on', you know? Stuff like that-that's why I feel uncomfortable talking to people. They look at me differentlylike I am different (R13).

R13's reflection can be understood in terms of Honneth's ideas of "trust in oneself" (2001, p. 48). In this sense the public refusal to offer R13 any "affective acceptance or encouragement" as she goes about her daily life might be part of the reason for her lack of emotional or bodily self-assurance (2001, p. 48). Understanding this as a raced mode of social exclusion comes from linking R13's story to the earlier work on stereotypes (Langton, 1995) and the settler Australian habit of marking Indigenous people as lacking, in this case in terms of bodily comportment.

Many of the respondents appreciate the value of material success but this is weighed against the loss of culture and, for many respondents, the cost is judged to be too high. As R21 noted about some Indigenous people: "I actually looked down on people and feel sorry for them because at the end of the day they are just in it for the money...." This feeling sorry for those caught in a trap of money is compounded by a perception that the neo-liberal offer of wealth and status in return for work in the formal economy is not worth it. They perceive the stress that accompanies this offer, and reject it, because of the stress that already exists in their lives. One respondent observed: "White people...they are like a slave, you know, to their work" (R17). A similar point was made by R26: "White people stress to the point where they are like [need] medications to calm themselves down" (R26). For these respondents, the neo-liberal offer of material wealth in exchange for a lifetime of hard work is both a false promise and one which is fundamentally irrational and unbalanced. It leads to neglect of the things that matter, which are caring for land and family.

R30's comment uses a temporal/spatial metaphor to describe Indigenous/settler Australian relations. She tells how "stuff" - her culture-is "cram[med] or "squeez[ed]" into the gaps around dominant settler Australian practices, in this case employment and sport.

This experience of efforts to do "what we're supposed to be doing" and "just not working" was closely associated with feelings of self-blame for some respondents. This was especially true of some male respondents, who used the term "shame job" to describe how dealing with balanda often made them feel. The hegemonic nature of White cultural norms and values, serve here as a form of symbolic violence, resulting in a widely expressed sense of inadequacy and failure. Some of this emotion is conveyed in this story told by an Indigenous Darwin resident from southern Australia. He explained a conversation with his cousin where she said:

"You know, I was almost in tears the other day" and I'm like "Why?" and she said "because an old Aboriginal man is out the front and the bouncer asked him to move away from the door". I said "oh yeah' and she said "and he just stood there so the bouncer kicked him out onto the road". You know things like that and just comments (R29)

This multidimensional narrative of loss is matched by an equally multidimensional narrative of resistance that took many forms including apathy, withdrawal, separation, detachment and political activism. This was often allied to the denial of the legitimacy of White governance (Hage, 1998), not only because of the legacy of colonisation, but also because of cynicism about White politics, the failure of the state's efforts to address the needs of Aboriginal people and its unresponsive and cruel administrative systems.

For many respondents, Western democratic principles of consultation and political inclusion mask a reality of denial and exclusion:

They call this a democracy. So they tell us we're living in a democracy and you have freedom of speech and that's exactly the trick, the con is to let you talk and talk and talk and talk and talk....Democracy allows you-gives you the illusion that you're being heard and...respected....This is a regime to me, a regime, 'Englishism' - a machine that's been going on and it's never gone stop....I don't like the word Australia because it doesn't include us. It doesn't fit our-you know the Aussie dream-l'm not in that Aussie dream (R38). 
For some respondents, the sense that the state's institutions were not working for Aboriginal people extended to organisations focused specifically on serving them-colloquially known in Australia as the 'Aboriginal industry'. This remark was typical of that view: "The Aboriginal industry is a source of exploitation that helps White people, not Aboriginal people" (R1). Here the participant is clear that employment is not a matter of social recognition as an equal but a replication of old patterns of subordination.

The sense of government ineffectiveness is welldescribed by R19:

I think the actual people in the government need to sit down and sort it out properly, not go around in circles. At least have a goal to get one thing accomplished, not just sit there and talk and talk and talk.

Anger at the government's inhumane application of rules is captured in a politically active respondent's account of the Federal government's lack of mercy in its response to the request of an asylum seeker held in a detention centre to visit his dying father in Australia.

They had a petition...64,000 people-to bring out a son for a dying bloke in Darwin. A young fella to bring his old man who was passing away. All they wanted to do is bring him (the young man) out so he could see (his father). They wouldn't do it. But because they block you, they create that wall, White picket fence again...So he couldn't come out here and his father passed away....So I think that's cruel. (R19)

Here the state's rigid application of administrative rules is linked directly to the broader unwillingness of settler institutions to respond to the higher moral order of human rights that contributes to Indigenous social exclusion.

Many of these respondents felt that although White culture offered many material advantages this has come at the cost of a loss of the ontological security that came from a culture rooted in ancient traditions. They saw settler culture as lacking a firm foundation because it is always changing and people are too self interested and disconnected from one another and too self-interested. From their perspective settler Australians are lost because of the weakness and relative nature of settler Australian values, as indicated by this comment: "I still think there's a feeling of loss there and disconnection.... On the surface you're happy with this money and this car and this house, but, yeah, I don't think so" (R12). The term "dollar dreaming" was often used to describe perceptions of the materialism and consumption that nearly all respondents believed lay at the heart of White culture. One respondent observed that the source of belonging within White cul- ture, came not from membership of a cultural group but from labour market position. Respondents often compared this unfavourably with the sense of connection to family and country that prevailed in Aboriginal culture and which was a source of strength and pride. They saw Australian culture as demanding an unacceptable trade off between material success and meaningful relationships: "People give up their family, they feel sad, they get homesick but they get a nice house" (R8). Another commented on the irrationality of hyperconsumption: But I just don't understand why White people buy their homes, renovate it, get expensive stuff and then they're old all of a sudden, you know" (R10).

Respondents also felt that in their everyday interactions with settler Australians there was little understanding or acknowledgement of how well Indigenous people are doing in circumstances of colonisation and dispossession. A common remark was that whenever they try to talk about the past as a pathway to reconciliation it is misinterpreted as an excuse for any difficulties they had. Their perception was of dual standards that failed to acknowledge that the problems so widely rehearsed in the public sphere were also widespread in settler settings.

Respondents spoke of their sense that, having lost their land, they face constant pressure to change-and therefore lose-their culture. While determined to hold on to it they feel they never have a chance for their ways to be appropriately acknowledged and respected. Their experience is of always being on the losing side in the engagement with Euro-Australia. While they aspire to a better life, it comes at the cost of Aboriginal culture. One respondent talked about this in relation to cultural expectations to attend funerals and the difficulties this causes for employment. He said:

it always defaults to the expectation that that Aboriginal person must lose, give up that value, that expectation to attend that funeral. That's what it defaults to; the Aboriginal person must lose that value. [But] you can't just lose that value. (R35)

Here the respondent is pointing to his sense of the inalienable nature of culture-that to lose it is to deny an aspect of himself. His account captures both the incompatibility between neo-liberal demands for paid employment and Aboriginal cultural demands to pay respect to those who have passed and the sense of subjection to a fixed hierarchy that always subordinates Aboriginal values to White ones.

For many respondents, this sense of the odds being stacked against Aboriginal people carried a profound sense of powerlessness and loss of hope. One public space dweller, when asked about relations with White people, repeatedly said "same-same". She meant that whatever she tries to do to that involves White people it achieves the same unfair result. Another employed 
woman, described the impossibility of trying to live in the Aboriginal way in an environment that provides no spaces for this:

All that stuff that we're supposed to be doing. We're trying to do it but it's 'after'-after work or after the footy or you know. We're trying to cram, squeeze in our culture. We can't...do it, we can't. We do it-might have a barbeque now an' then and we try. It's just not working. (R30)

\section{Conclusion}

The narratives of the participants accumulate to produce a story about the ongoing rejection of Aboriginal people, values and culture by the dominant White settler population alongside their own rejection of the neo-liberal deal of individual advancement through economic pathways of employment and the accumulation of debt. They make visible an Indigenous truth organised around a radically different idea of the everyday and the meaningful. This co-exists with a quotidian and perpetual struggle to have these truths recognised in a geographic, cultural, economic, political and legal space ordered around a settler Australian social reality.

These narratives support arguments about the importance of intersubjective recognition because of the impact of misrecognition on social exclusion. They show how the lived and ubiquitous experience of mistreatment contributes to the inequitable distribution of material goods in the way Honneth has suggested:

The rules organizing the distribution of material goods derive from the degree of social esteem enjoyed by social groups, in accordance with institutionalized hierarchies of value, or a normative order. (2001, p. 54)

"Shame job" and segregation create a vicious circle of withdrawal and isolation that works in both directions. It reinforces social and physical distance, generates Indigenous resistance and strengthens settler Australian ignorance. Withdrawal and isolation then sustain the maintenance of differences in social and cultural capital that, in turn, reinforce barriers to social inclusion.

Future research will go more deeply into the data, especially in relation to analysing the perspectives of different social groups in areas including understandings of White values and lifestyles, views on White governance, including labour market participation and how intercultural relations can be improved. At this stage systematic analysis of the variation between groups such as long grassers, political activists and those in employment has not been undertaken and the focus has instead been on capturing some of the broad themes present in the majority of the interviews. While this paper has argued for the similarities in Aboriginal perspectives on race relations in Darwin, we anticipate that deeper analysis will reveal important differences between different groups.

\section{Acknowledgments}

Our thanks to Alex di Georgio and Kelly Pollard for assistance in the development of this article.

\section{Conflict of Interests}

The authors declare no conflict of interests.

\section{References}

Australian Bureau of Statistics. (2010). Indigenous disadvantage and selected measures of wellbeing. In Year book Australia 2009-10 (Cat. No. 1301.0). Retrieved from http://www.abs.gov.au/AUSSTATS/abs@.nsf/ Lookup/1301.0Feature+Article9012009-10

Australian Bureau of Statistics. (2013a). 2011 Census quickstats Darwin indigenous region. Retrieved from http://www.censusdata.abs.gov.au/census_services/ getproduct/census/2011/quickstat/7GDAR?open document\&navpos=220

Australian Bureau of Statistics. (2013b). 2011 Census quickstats Greater Darwin. Retrieved from http:// www.censusdata.abs.gov.au/census_services/getpro duct/census/2011/quickstat/7GDAR?opendocument \&navpos $=220$

Australian Government. (2012). Closing the gap: Prime Minister's report 2012. Canberra: Department of Prime Minister and Cabinet. Retrieved from http://www.fahcsia.gov.au/sa/indigenous/pubs/closi ng_the_gap/Documents/closing_the_gap_2012.pdf

Bessarab, D., \& Ng'andu, B. (2010). Yarning about yarning as a legitimate method in Indigenous research. International Journal of Critical Indigenous Studies, 3(1), 37-50.

Bretherton, D., \& Mellor, D. (2006). Reconciliation between Aboriginal and other Australians: The "stolen generations". Journal of Social Issues, 62(1), 81-98.

Chesterman, J., \& Galligan, B. (1997). Citizens without rights: Aborigines and Australian citizenship. Cambridge: Cambridge University Press.

Cunneen, C. (2008). Bringing Them Home and the contemporary criminalisation of Indigenous young people. Australia Indigenous Law Review, 12, 46-54.

Dunn, K. M., Kamp. A., Shaw, W., Forrest, J., \& Paradies, Y. (2010). Indigenous Australians' attitudes towards multiculturalism, cultural diversity, "race" and "racism". Journal of Australian Indigenous Issues, 13(4), 19-31.

Elder, C. (2007). Being Australian: Narratives of national identity. Sydney: Allen and Unwin.

Frankenberg, R. (1993). The social construction of Whiteness: White women, race matters. London: Routledge. 
Fraser, N. (2000). Rethinking recognition. New Left Review, 3. Retrieved from http://newleftreview.org/ II/3/nancy-fraser-rethinking-recognition

Fraser, N. (2001). Recognition without ethics? Theory, Culture \& Society, 8(2/3), 21-42.

Fraser, N., \& Honneth, A. (2003). Redistribution or recognition? A political-philosophical exchange. London: Verso.

Goot, M., \& Rowse, T. (2007). Divided nation: Indigenous affairs and the imagined public. Melbourne: Melbourne University Press.

Guilfoyle, A., Coffin, J., \& Maginn, P. (2010). “Make sure there is a shady tree": Participation and action research with Australian Aboriginal communities. Studies in Qualitative Methodology, 9(9), 213-240.

Gunstone, A. (2007). Unfinished business: The Australian formal reconciliation process. Melbourne: Australian Scholarly Publishing.

Habibis, D, (2013). Australian housing policy, misrecognition and Indigenous population mobility. Housing Studies, 28(5), 764-781.

Hage, G. (1998). White nation: Fantasies of White supremacy in a multicultural society. Sydney: Pluto Press.

Hartmann, D., Gerteis, J., \& Croll, P. R. (2009). An empirical assessment of whiteness theory: Hidden from how many? Social Problems, 56(3), 403-424.

Holmes, C. (2008). Being undesirable: Law, life and health in Darwin's long grass. Darwin: LNAC and NDLERF.

Honneth, A. (1995). The struggle for recognition: the moral grammar of social conflicts. Cambridge: Polity.

Honneth, A. (2001). Recognition or redistribution? Changing perspectives on the moral order of society. Theory, Culture \& Society, 18(2/3), 43-55.

Langton, M. (1993). "Well I heard it on the radio and saw it on the television": An essay for the Australian Film Commission on the politics and aesthetics of filmmaking by and about Aboriginal people and things. Sydney: Australian Film Commission.

Langton, M. (2012). The quiet revolution: Indigenous people and the resources boom. ABC Boyer Lectures. Retrieved from abc.net.au/radionational/boyer lectures

Larkin, S. (2011). Indigenous perspectives: Enriching scholarship and practice. Australian Social Work, 64(1), 2-5.

Lister, R. (2004). A politics of recognition and respect: involving people with experience of poverty in decision-making that affects their lives. In J. Anderson \& B. Sim (Eds.), The politics of inclusion and empowerment. New York: Palgrave.

Martin, K. (2008). Please knock before you enter: Aborig- inal regulation of outsiders and the implications for researchers. Teneriffe: Post Pressed.

Mellor, D. (2003). Contemporary racism in Australia. Personality and Social Psychology Bulletin, 29(4), 474-486.

Miller, S. M., \& Savoie, A. J. (2002). Respect and rights: Class, race and gender today. Oxford: Roman \& Littlefield.

Morrison, Z. (2010). On dignity: Social inclusion and the politics of recognition (Social Policy Working Paper No. 12). Melbourne: Brotherhood of St Laurence, Centre for Public Policy, ,

Prout, S. (2012). Urban myths: Exploring the unsettling nature of Aboriginal presence in and through a regional Australian town. Urban Policy and Research, 29(3), 275-291.

Roulston, K. (2010). Reflective interviewing: a guide to theory and practice. London: Sage.

Rowse, T. (2009). Official statistics and the contemporary politics of Indigeneity. Australian Journal of Political Science, 44(2), 193-211.

Saxton, A. (2004). Whiteness and reconciliation: A discursive analysis. Australian Psychologist, 39(1), 1423.

Smith, L. T. (2001). Decolonizing methodologies: Research and Indigenous peoples. London: Zed Books.

Stolper, D., \& Hammond, R. (2010). Reconciliation barometer. Reconciliation Australia. Retrieved from http://www.reconciliation.org.au/getfile?id=1303\&fil e=Australian+Reconciliation+Barometer+2010++ full+report.pdf

Taylor, C. (1992). The politics of recognition. In A. Gutmann (Ed.), Multiculturalism and "the politics of recognition". Princeton: Princeton University Press.

Thompson, S. (2005). Is redistribution a form of recognition? Comments on the Fraser-Honneth debate. Critical Review of International Social and Political Philosophy, 8(1), 85-102.

Walter, M. (2012). Keeping our distance: NonIndigenous/Aboriginal relations in Australian society. In Australian Survey of Social Attitudes (pp. 15-32). Canberra: Australian National University Press.

Walter, M., Taylor, S., \& Habibis, D. (2011). How White is social work in Australia? Australian Social Work, 64(1), 6-19.

Wilson, S. (2008), Research is ceremony: Indigenous research methods. Halifax: Fernwood.

Worby, G., \& Rigney, L.-I. (2006). Sharing space: Indigenous and non-Indigenous responses to story, country and rights. Perth: API Network.

Zurn, C. F. (2003). Identity or status? Struggles over recognition in Fraser, Honneth and Taylor. Constellations, 10(4), 519-537. 


\section{About the Authors}

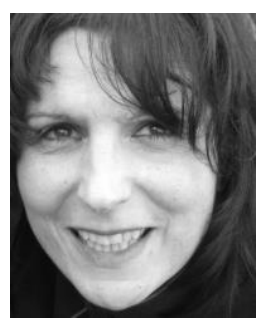

\section{Dr. Daphne Habibis}

Associate Professor Daphne Habibis is Director of the Housing and Community Research Unit at the University of Tasmania. She is a sociologist who has published widely on inequality especially in relation to social housing and Aboriginal issues. Recent major research projects concern Aboriginal and Euro-Australian race relations, welfare conditionality in Aboriginal housing, and tenancy management on remote Aboriginal communities.

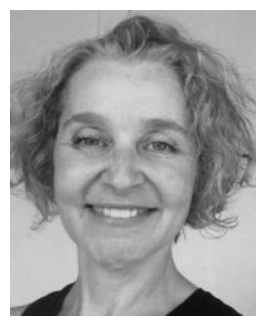

\section{Penny Taylor}

Penny Taylor is the Head Researcher at the Larrakia Nation Aboriginal Corporation, a peak body for the Larrakia people - the descendants of the Traditional Owners of the land on which Darwin is built. She is currently undertaking a PhD on race relations in Darwin. She has developed multimedia resources that engage with Indigenous people and the issues they see as important to living in Darwin. Most recently she produced Darwin Radio Diaries (2013). She is the also co-author of an autobiography of a senior Aboriginal Lawman from East Arnhem.

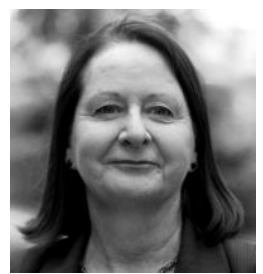

\section{Dr. Maggie Walter}

Maggie Walter (PhD) is a descendant of the people from tebrakunna country in North Eastern Tasmania. She is also Professor of Sociology and the inaugural Pro Vice-Chancellor of Aboriginal Research and Leadership at the University of Tasmania. She has published extensively in the field of inequality, race relations and family especially as they relate to Indigenous peoples in Australia and elsewhere.

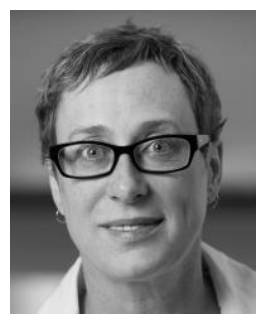

\section{Dr. Catriona Elder}

Associate Professor Catriona Elder is a scholar of Australian Studies who thinks about Australia in an international context. Her work is based around intercultural exchange. She focuses on issues of cultural difference, for example: Indigeneity and reconciliation, immigration and racism. Current research projects are related to Indigenous wellbeing in relation to national inclusion and exclusion and work on mixed-race families in Australia. 